\title{
Drug-related Deaths in England and Wales
}

\section{Dr Alan Farnworth MSc MBChB DMCC DipFHiD DipFMS, Specialist Trainee Year 2, Histopathology}

\section{INTRODUCTION}

Drug-related deaths occur in a range of different circumstances attracting significant media, political and public interest. The number of drug-related deaths is increasing and there is an immediate need to explore why these deaths are occurring, who is being affected and to create strategies to help tackle this problem. The coroner's investigation involves a wide range of professionals including; pathologists, toxicologists, clinicians and forensic medical examiners. The information gained from the coroner will form the basis for national statistics used in monitoring patterns and trends in drug-related deaths. This information is then used to guide policy making and create strategies to try to prevent drug-related deaths.

\section{OFFICE FOR NATIONAL STATISTICS}

Within England and Wales the Office for National Statistics (ONS) facilitates research into drug-related deaths derived from the national mortality database. Drug-related deaths are usually registered following a coroner's inquest and the ONS uses codes of all causes of death on the death certificate using the International Statistical Classification of Disease and Related Health Problems (ICD). An underlying cause of death is selected using automated ICD coding rules. ${ }^{1}$ The underlying cause of death is defined by the World Health Organisation as:

- The disease or injury that initiated the train of events directly leading to death, or

- The circumstances of the accident or violence that produced the fatal injury (or poisoning)

The ONS definition of deaths ${ }^{1}$ related to drug poisoning includes:

- Accidents, suicides and assaults involving drug poisoning

- Drug abuse

- Drug dependence
It excludes adverse effects of drugs such as:

- Anaphylactic shock

- Transport accidents where the driver was under the influence of drugs

- A small number of assaults involving drugs due to lack of information available to the ONS

- Deaths by chemical and noxious substances

The ONS definition of drugs misuse:

- Deaths where the underlying cause is drug abuse or drug dependence

- Deaths where the underlying cause is drug poisoning and where any of the substances controlled under the Misuse of Drugs Act 1971 are involved

\section{PATTERNS AND TRENDS}

In 2016 in England and Wales there were 3,744 drug poisoning deaths including illegal and legal drugs, of these deaths 2,593 were drug misuse deaths, involving controlled drugs, which is the highest since comparable records began in 1993. ${ }^{2}$ The majority of drug-related deaths occur in males although both sexes have seen a steady increase in the number of drug-related deaths since 1993 (Figure 1). The number of deaths in males has and remains to be higher than females with 2,572 deaths in males compared to 1,172 in females registered in 2016 (Figure 2). According to the Crime Survey for England and Wales 2015 to $2016^{3}$ males were more likely to take drugs than females. There was a higher percentage of males (12\%) aged 16 to 59 who had taken illegal drugs than females (5\%). In males $86 \%$ of drug misuse deaths were due to accidental poisoning whereas this figure was $72 \%$ in females in 2016. Females are more likely to have an underlying cause of suicide than males with $23 \%$ of female drug misuse deaths due to suicide and $11 \%$ in males registered in 2016. (Figure 3).

Illegal drugs account for the largest proportion of drug-related deaths in 2016, accounting for 2,692 deaths

75

Rate per million

50

25

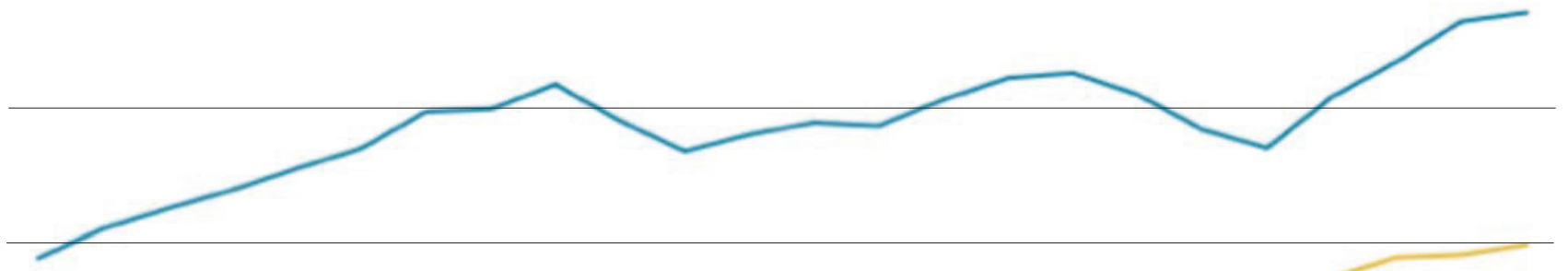

0

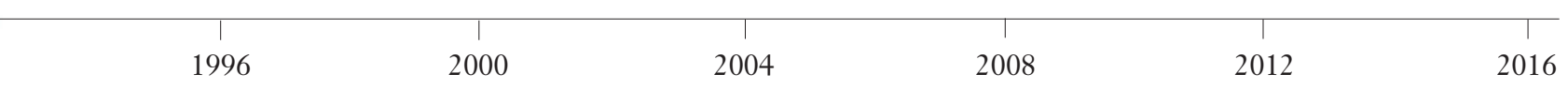

- Males - Females

Figure 1: Age-standardised mortality rates for deaths related to drug misuse, by sex, deaths registered in 1993 to 2016 in England and Wales. Source: Office for National Statistics. 


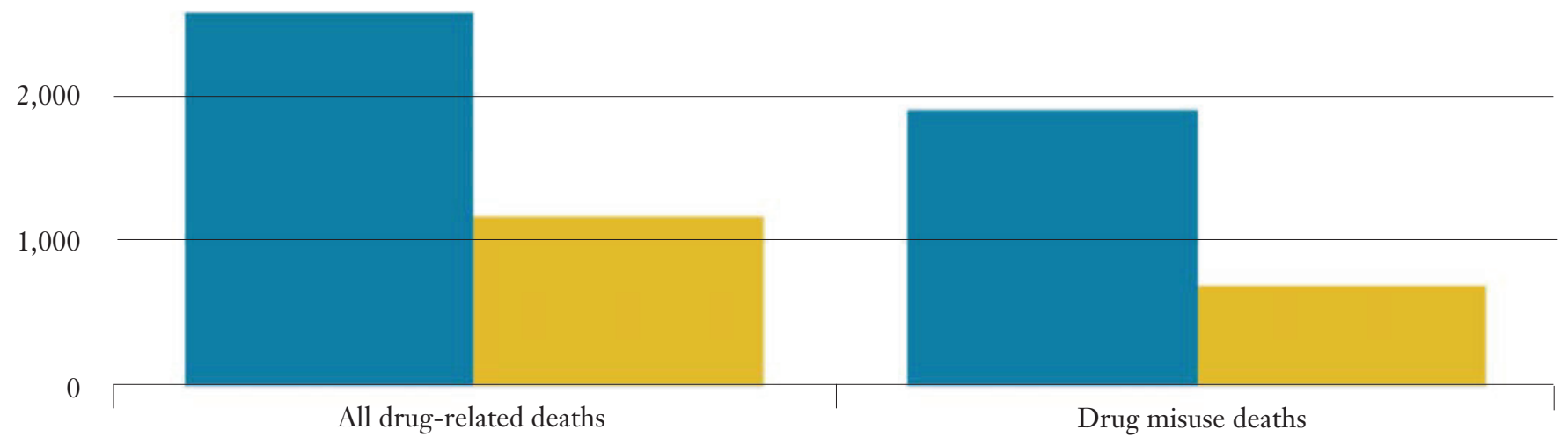

Males Females

Figure 2: Number of deaths from drug poisoning and drug misuse, by sex, deaths registered in England and Wales in 2016. Source: Office for National Statistics.

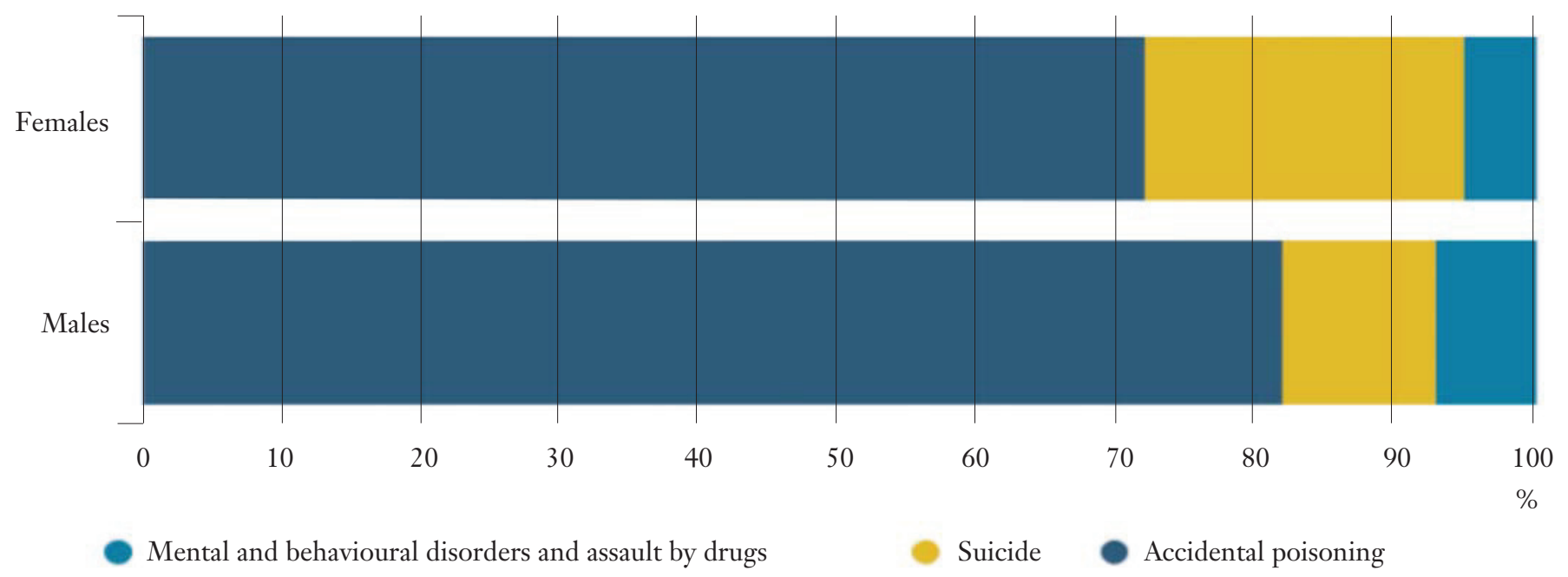

Figure 3: Percentage of drug misuse deaths, by underlying cause and sex, deaths registered in England and Wales in 2016. Source: Office for National Statistics.

out of 3,744 . Of all the illegal drugs involved opiates were responsible for 2,038 deaths in 2016. The trends in new psychoactive substances are also on the increase. In 2016 there were 123 deaths due to new psychoactive substances out of the total drug-related deaths of 3,744 (0.03\%) (Table 1). There were 1,052 deaths registered due to legal drugs in 2016 which is less than half of the deaths due to illegal drugs. In the year 2015/16 there were 1 in 12 adults (16 to 59 years old) in England and Wales that had taken an illicit drug at some point during the year. ${ }^{5}$

Cannabis is by far and large the most commonly used illegal drug, powder cocaine is second in the adult age group, (16 to 59 years old) however within the young adult group (16 to 24 years old) it comes third after ecstasy. The use of cocaine saw an increase in the 1990s but has since remained reasonably stable in the 2000s contrary to generally decreasing trends seen overall. ${ }^{5}$
A frequent user is defined as somebody taking a drug more than once a month ${ }^{5}$ and it is known that the mortality rate is higher in frequent users than in the general population. ${ }^{4,5,6}$ There were $3.3 \%$ of adults aged 16 to 59 (approximately 1.1 million) classified as frequent drug users with higher proportions in the 16 to 24 year old age group. Infrequent drug use in cannabis, cocaine and ecstasy is the most common pattern of drug use in adults. There are clear downward trends seen in frequent use of cocaine and ecstasy but cannabis appears to remain stable. The use of opiates is responsible for the biggest proportion of drug related deaths however there was only $0.1 \%$ of those surveyed using opiates. ${ }^{5}$

Drug-related death patterns and trends do not correlate well with the patterns seen in drug use. The trends in fact appear to be the opposite; increasing rates of drug-related deaths and decreasing numbers of drug users. 


\begin{tabular}{|l|c|c|c|c|c|}
\hline \multicolumn{1}{|c|}{$\begin{array}{c}\text { ALL DRUG } \\
\text { POISONING DEATHS }\end{array}$} & $\mathbf{2 0 1 2}$ & $\mathbf{2 0 1 3}$ & $\mathbf{2 0 1 4}$ & $\mathbf{2 0 1 5}$ & $\mathbf{2 0 1 6}$ \\
\hline Any opiate & 1,290 & 2,955 & 3,346 & 3,674 & 3,744 \\
\hline Heroin and/or morphine & 579 & 1,592 & 1,786 & 1,989 & 2,038 \\
\hline Methadone & 414 & 765 & 952 & 1,201 & 1,209 \\
\hline Tramadol & 175 & 220 & 240 & 208 & 413 \\
\hline Oxycodone & 37 & 51 & 51 & 51 & 75 \\
\hline Fentanyl & 22 & 22 & 40 & 34 & 58 \\
\hline Cocaine & 139 & 169 & 247 & 320 & 371 \\
\hline Any amphetamine & 97 & 120 & 151 & 157 & 160 \\
\hline $\begin{array}{l}\text { Any new psychoactive } \\
\text { substance }\end{array}$ & 55 & 63 & 82 & 114 & 123 \\
\hline Any benzodiazepine & 284 & 342 & 372 & 366 & 406 \\
\hline Pregabalin & 4 & 33 & 38 & 90 & 111 \\
\hline Gabapentin & 8 & 9 & 26 & 49 & 59 \\
\hline All antidepressants & 468 & 466 & 517 & 447 & 460 \\
\hline Paracetamol & 182 & 226 & 200 & 197 & 219 \\
\hline Propranolol & 39 & 46 & 54 & 55 & 45 \\
\hline
\end{tabular}

Table 1: Number of drug-related deaths where selected substances were mentioned on the death certificate, deaths registered in England and Wales 2012-2016. Source: Office for National Statistics.

\section{THE ROLE OF THE CORONER}

A coroner is an independent judicial officer who is responsible for investigating the cause of deaths within their jurisdiction. Under Section 5 of the Coroner's and Justice Act $2009^{7}$ coroners inquiries are to determine:

- Who the deceased was

- How, when and where the deceased came by his or her death

- The particulars required by the Births, Death and Registration Act $1953^{8}$ to be registered concerning the death

An inquest will be open if:

- There is suspicion that the death was violent or unnatural

- The cause of death is unknown

- The death occurred in custody or state detention

- The deceased was not seen by a doctor during the 14 days before death

- The deceased was not seen by the doctor issuing the medical certificate

The coroner holds responsibility for investigating and determining the cause of death and working with a number of different professionals including; pathologists, toxicologists, technical laboratory staff, medical examiners and clinicians. These professionals report their findings to the coroner who reviews all the evidence and makes their verdict.

\section{THE ROLE OF THE PATHOLOGIST}

The pathologist, ordered by the coroner (England and Wales) or procurator fiscal (Scotland) performs the post mortem in the investigation of drug-related deaths which requires a collaborative investigation with a toxicologist. The pathologist performs the post mortem to confirm, exclude or evaluate any trauma or natural disease and to determine a cause of death. They may help establish suspicious circumstances and take samples for the toxicologist to test for the presence and quantity of any drugs. Post mortems in drug-related deaths can be challenging for both the pathologist and toxicologist for the following reasons:

- The substance taken may be unknown

- There may be more than one substance involved

- The route by which the substance was taken may be unclear

- There may be a lack of information regarding the lethal dose of the drug used 
- The post mortem may not show any gross or microscopic abnormalities and the only abnormalities may be the toxicology results

- Post mortem changes to the body affecting the drug concentration, presence and distribution

- The time period since taking the drug may be too long or too soon for toxicological analysis

- The substance used may be quickly broken down leading to difficulties in detecting the substance ${ }^{9}$

There is often no characteristic lesion found at post mortem making the post mortem examination difficult and reliant on information relating to the circumstances of death. In cases where there is a lack of indicative or suggestive history, a blind post mortem is performed which requires more extensive sampling for toxicological analysis. This can be difficult and expensive. Certain findings may be useful indicators but the interpretation of the toxicological analysis is of paramount importance. The findings from post mortem may help in determining and understanding the habits of the drug user through the presence of any chronic signs such as:

\begin{tabular}{|c|c|}
\hline Injection sites & Emaciation \\
\hline Infection sites & Skin ulceration \\
\hline Necrosis & Loss of phalanges due to emboli \\
\hline $\begin{array}{l}\text { Bruising (around old } \\
\text { injection sites) }\end{array}$ & Venous thrombosis \\
\hline Constricted pupils & Pulmonary oedema \\
\hline
\end{tabular}

Modern medicines by design cause little irritation to the tissues and gastrointestinal system, they are designed to be ingested and then broken down into their metabolites to have their pharmacological effect on the target organ. If a medicine is taken in sufficient quantities to cause death then their constituents will have had their effect on the organs and tissues but often show no damage to the gastrointestinal tract. This means that often at post mortem there will be no gross or microscopic features of any damage. Death due to a medicinal compound is often due to cardiorespiratory failure resulting in non-specific findings at post mortem indicating no obvious cause of death. These may include:

$\begin{aligned} & \text { Acute congestive } \\ & \text { cardiac failure }\end{aligned}$
Cerebral oedema Genary oedema
Petechial haemorrhages

The importance of toxicology in drug-related deaths means that a wide range of samples should be taken at post mortem even if the primary administration route is known. This is to ensure there is enough material to be adequately tested to provide accurate and reliable information regarding any drugs present (legal and illegal). Samples that may be taken include:

$\begin{array}{lll}\text { Venous blood } & \text { Stomach contents } & \text { Urine } \\ \text { Vitreous humour } & \text { Liver } & \text { Bile } \\ \text { Cerebrospinal fluid } & \text { Brain } & \text { Kidney } \\ \text { Hair } & \text { Nasal swabs } & \text { Nails } \\ \text { Skin } & \text { Muscle } & \\ \text { Injection site } & \text { Non-injection site } & \end{array}$

Fluids usually provide more recent information regarding the drugs taken. As the tissue sampled becomes more solid, the length of time the drug history can be established increases, finger and toe nails can provide a 6 to 12 month drug history.

\section{THE ROLE OF THE TOXICOLOGIST}

The toxicologist will perform the analysis of samples gathered from the post mortem examination producing qualitative and quantitative results which will be interpreted in collaboration with the ante mortem history and post mortem findings. Their role is to try and answer the question; did a drug cause or contribute to the death? The toxicologist will communicate the result to the pathologist indicating the substances present, their toxic and therapeutic ranges, presence in the samples received and their relevance, highlighting considerations such as decline in concentrations due to post mortem degradation, ${ }^{10}$ post mortem changes in drug concentrations, site and time related changes as well as issues with tolerance. ${ }^{11}$ Certain drug addicts, who have developed tolerance to drugs, may have drug concentrations in life high enough to kill a naïve user.

It is known that for some drugs the concentrations alter in the post mortem period often increasing when the sample is taken from areas where there may be diffusion from gastrointestinal contents or in drugs with high fat solubility. ${ }^{12}$ Other drugs are known to decrease in concentration due to them being unstable and potentially degrading. ${ }^{13}$ The exact lethal dose for most drugs is unknown due to difficulties extrapolating post mortem concentrations to ante mortem concentrations.

There are a lot of factors that can influence the levels of drugs in life and death and there is no consistent or reliable comparison between drug concentrations in life and death. This makes the interpretation of the results difficult.

\section{STRATEGIES TO REDUCE THE NUMBER OF DRUG-RELATED DEATHS}

How we use drugs is an important social, political and health issue. Any policies, solutions or legislation are under constant scrutiny and review. The public do not have confidence in government strategies in tackling illicit drug use; over half of the UK population surveyed in 2011 thought the government's approach to be totally ineffective. ${ }^{14}$

The biggest cause of drug-related deaths is opiates and deaths are more common in frequent users. The overall decline seen in drug use is likely not to have affected the drug-related death rates as the opiate users only make up $0.1 \%$ of the total amount of drug users, despite accounting for over half of all drug-related deaths. The commonest type of death in drug abusers is accidental poisoning which accounts for over half of the total types of death. Working to prevent the most common type of death, of the most common drug involved, in the most frequent users has the potential to have a significant impact on drug-related deaths.

One recent strategy involves the use of naloxone in the community. Naloxone is a drug used to reverse the 
effects of heroin and morphine in the circumstances of a life-threatening overdose. The naloxone is administered in the case of overdose to prevent death. This then creates opportunities to implement drug cessation programmes, treatment plans and cessation advice. In October 2015 the Advisory Council on the Misuse of Drugs (ACMD) advised the government to ease the restrictions on who can be supplied with naloxone in order to facilitate take home naloxone programmes. In 2015 the rules governing the administration of naloxone were relaxed in order to permit these programmes to be set up in numerous areas where people at risk are trained in how to use it as well as friends and families and at numerous treatment centres. One such scheme in Newcastle saw naloxone being used in the community eight times in the first year, potentially saving eight lives. ${ }^{15}$ The full extent of the impact had by these schemes is yet to be fully understood but early results are showing the scheme is being used and may potentially help to reduced drug-related deaths.

\section{CONCLUSION}

The issues surrounding drug-related deaths are complex and require a multi-disciplinary approach to better understand the problem and to develop strategies to try to tackle this issue. Understanding how drug-related deaths occur allows for more accurately targeted strategies. There are numerous programmes attempting to reduce the number of drug-related deaths and there is a need for more. It is essential that accurate investigation of drugrelated deaths is performed in order to drive these targeted strategies to help solve this problem.

\section{REFERENCES}

1. World Health Organisation. International statistical classification of diseases and related health problems. 10th Revision (ICD-10), World Health Organisation, 2016.

2. Office for National Statistics. Deaths related to drug poisoning in England and Wales: 2016 registrations. Office for National Statistics, August 2017.

3. Home Office. Drugs misuse: findings from the 2015/16 crime survey for England and Wales. Home Office National Statistics, 2nd ed. July 2016.

4. Joe GW, Lehman W, Simpson D. Addict death rates during a four-year post-treatment follow-up. American Journal of Public Health 1982;72:703-709. Available at: https://ajph.aphapublications.org/doi/ pdf/10.2105/AJPH.72.7.703 (accessed 18.2.19).

5. Ghodse H, Oyefeso A, Kilpatrick B. Mortality of drug addicts in the United Kingdom. International Journal of Epidemiology 1993;27:473-478. Available at: https://academic.oup.com/ije/ article/27/3/473/625414 (accessed 18.2.19)

6. Gossop M, Stewart D, Treacy S, Marsden J. A prospective study of mortality among drug misusers during a 4-year period after seeking treatment. Addiction 2002;97:39-47.

7. Great Britain. Coroners and Justice Act 2009. Available at: https://www.legislation.gov.uk/ ukpga/2009/25/contents (accessed 18.2.19).
8. Great Britain. Births Deaths and Registration Act 1953. Available at: http://www.legislation.gov.uk/ ukpga/Eliz2/1-2/20 (accessed 18.2.19).

9. Saukko P, Knight B. Knight's forensic pathology, 3rd ed. London: CRC Press, 2004.

10. Payne-James J, Jones R, Karch SB.. Simpson's forensic medicine, 13th ed. London: CRC Press, 2011:chapter 18.

11. FernerRE.Post-mortemclinicalpharmacology.British Journal of Clinical Pharmacology 2008;66(4):430 443.

12. Pounder DJ, Jones GR. Post-mortem drug redistribution - a toxicological nightmare. Forensic Science International 1990;45:253-263.

13. Robertson MD, Drummer OH, Stability of nitrobenzodiazepines in post-mortem blood. Journal of Forensic Science 1998;43(1):5-8.

14. BMA Board of Science. Drugs of dependence: the roles of medical professionals. London: BMA, 2018:chapter 2. Available at: https://www.bma.org. uk/collective-voice/policy-and-research/publicand-population-health/illicit-drug-use/full-report (accessed 18.2.19).

15. Local Government Association. Preventing drug related deaths. Local Government Association, May 2017. Available at: https://www.local.gov.uk/ preventing-drug-related-deaths (accessed 18.2.19).

\section{DECLARATIONS}

There is no conflict of interest.

This article has not been published elsewhere.

Correspondence to: alan.farnworth@mbht.nhs

This paper serves as a general interest article exploring the issues with drug-related deaths. The article aims to educate readers about the roles of the coroner, pathologist, and toxicologist and how post mortem information helps inform and drive strategies to belp tackle this increasing problem. Readers will appreciate the size of this growing problem and how strategies are derived from post mortem examinations. 